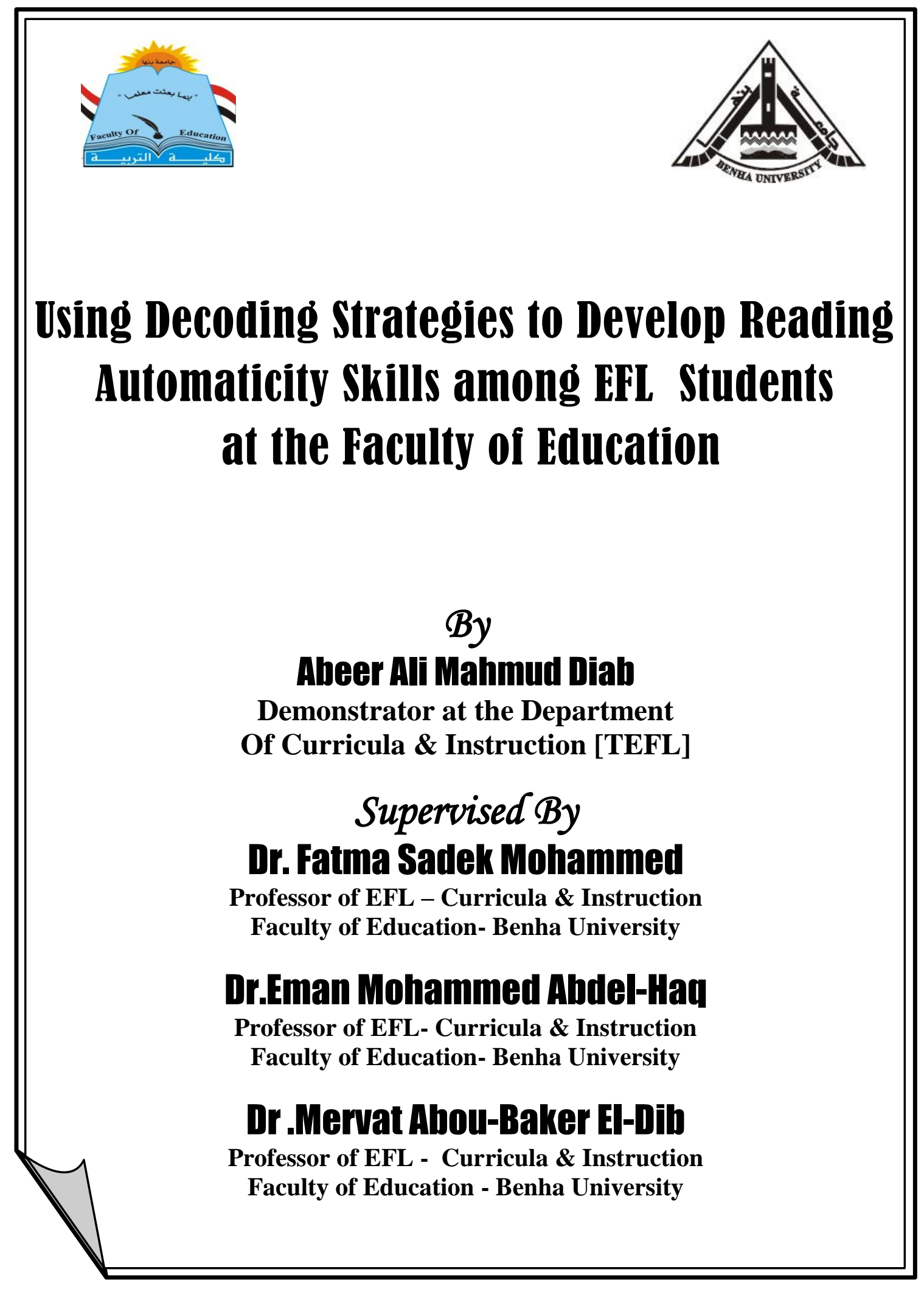




\section{Using Decoding Strategies to Develop Reading Automaticity Skills among EFL Students at the Faculty of Education}

By

Abeer Ali Mahmud Diab

Demonstrator at the

Department

Of Curricula \&

Instruction [TEFL]
Supervised By

Dr.Fatma Sadek Mohammed

Professor of EFL - Curricula \& Instruction

Faculty of Education- Benha University

Dr.Eman Mohammed Abdel-Haq

Professor of EFL- Curricula \&I nstruction

Faculty of Education- Benha University

Dr.Mervat Ahoul-Baker El-Dihb

Professor of EFL - Curricula \& Instruction

Faculty of Education - Benha University

\section{Ahstract}

This study aimed at investigating the effect of using Decoding Strategies to develop reading Automaticity skills among EFL students at the Faculty of Education. The study followed a pre-post experimental one group design. The participants were 30 students of second year enrolled in English section at Faculty of Education, Benha University .To determine the most important and required EFL reading automaticity skills for the study sample, a list of EFL reading automaticity skills was designed and validated by a number of EFL jury members. A pre and post EFL reading automaticity test was designed. Students were pretested, to determine their entry level of EFL reading automaticity skills. They were trained through the sessions' program on how to develop their reading rate and comprehension. The test was re-applied on the participants to assess the progress in their level of performance in reading automaticity. Results of the study revealed that there were a significant difference in the pre post assessment of EFL reading automaticity skills in favor of the post assessment. Accordingly, the program was effective in developing the EFL reading automaticity skills. 
Key words: Decoding Strategies, EFL Reading Automaticity Skills Introduction: $\square$

Reading is an active process that comprises the interaction between a reader and a text to get meaning from printed words. To develop reading skills there are some basic skills need to be practiced: phonemic

awarness,phonics,vocabulary,fluencyandfinallyreadingcomprehen sion.Phonemic awareness is the ability to hear,identify,and manipulate sounds in spoken language. Phonics knowledge is the understanding that there are predictable relationships between written letters and spoken sounds and the usage of this relationship to read and write words. The third pillar is vocabulary that is very important to understand text and get meaning of what is read. Finally, fluency is the ability to read a text accurately ,quickly, smoothly and with good expression.(National Reading Panel, 2000\&Mazur, 2005)

Reading fluency is comprised of several linguistic elements as it is the ability to project the word with natural pitch,stress, and juncture of the spoken word on written text, automatically and at a natural rate.When it is applied during reading silent reading comprehension becomes more possible. It is far than reading letters and symbols out loud;it is bedrock of comprehension. Therefore ,reading fluency is thestepping stone to the goal of comprehension, the ultimate purpose of reading .(Hacker, 2008). Reading fluency is considered as one of the most important variables for successful literary development .It is essential component in any reading program because it is a defining characteristics of good readers. While lack of fluency is often associated 
with poor readers .Accordingly, it is the bridge between word identification and text comprehension(Rasiniski,2012).

Reading automaticity is considered as one of the most important skills of reading fluency. Automaticity refers to the processing of information or the application of a skill with a little conscious attention or effort .When any skill has reached automaticity, four basic elements are demonstrated: speed, accuracy, economy of effort, and flexibility. In contrast, the processing of information or execution of a task that has not become automatic requires significantly more conscious thought and thought in addition to considerably more of an individual's attention and working memory capacity (Sargent,2002)

According to, (Luckner and Urbach,2011) moving to reading automaticity, requires transmitting through four phases. The first phase(a)unconscious incompetence in which one feels that he is incompetent at something but don't even know. The second phase is the conscious incompetence phase in which one tries a new skill and realize that he is not able to do it, but at the same time he feels much worse than before. Then the conscious competence phase :one can manage to execute a new skill, but it requires conscious attention , and if one is distracted ,he makes mistakes. The final phase is the unconscious competence in this phase the new skill comes naturally and thoughtlessly .In this phase, one can master a new habit and no longer have to use the conscious mind to focus on it.Thus,for becoming automatic reader, one should process text smoothly, identify and understand words easily, efficiently and rapidly ,discern syntax ,and focus on meaning 
According to Automaticity theory and verbal efficiency theory ,growth in fluency more especially in the speed component facilitates reading comprehension. That occurs when word recognition becomes faster it eventually becomes automatic ,allowing the attention that was once required for the task of word decoding to be devoted to comprehension(Clauda\&Guthrie,2007).Moreover, Samuels (2006), indicated that automatic word recognition is critical component of fluency and fluency role in the comprehension of the text .This is the reason that isolated word recognition assessments can be used to determine oral reading fluency .On the other hand, ineffecient word recognition hinders comprehension because readers are spending the majority of their cognitive resources on word level processes .Once the word recognition processes have become automatic, readers can decode and comprehend simulatiously. Because of this reciprocal relationship, there is often a high correlation between reading rate and the overall reading ability.

Reading rate appeared to reflect students' ongoing development of automaticity in their decoding, which can be developed through practice and assisted readings. If teachers provide the kind of instruction in fluency that works ,then fluency, comprehension, and rate will improve. If teachers choose instead to focus primarily on developing students 'reading rate at the expense of reading with expression, meaning, and comprehension, students may read fast but with insufficient comprehension. Their goal may be to get from one point in the text to another as fast as possible, without understanding the nuances of meaning in the text. Similarly ,teachers need to be cautious in using 
reading rate to assess English Language Learners(ELLS).Many ELLS can be deceptively fast and accurate in their reading, yet demonstrate little understanding of the text. Teachers cannot assume that such students are progressing well in reading based solely on their reading rate. Other issues such as vocabulary and language proficiency may impede the students' growth in reading and require instructional intervention.(Rasiniski,2004 ;Hudson,Lane\&Pullen,2005).

Assessment of reading automaticity includes tests of sight-word knowledge or tests of decoding rate and comprehension as important two sub-skills of reading automaticity. Measurement of reading rate is most typically accomplished through timed readings. Timings of a student's reading of connected text allows the teacher to observe the number of words read correctly and the number of errors made in a given time period .Data from timed readings are usually recoded on a timing chart. Timed readings can be used to measure and increase word-reading accuracy and passage reading rate. Timed readings are conducted using passages that are at independent reading level ,passages that students can read with 95\% accuracy or above. (Hudson, Lane and Pullen,2005)

There are a number of interventions that have shown to improve reading automaticity, that aim to increase students' accurate rate and comprehension. A key aspect of these interventions is that they provide learners with scaffolded opportunities to read connected texts with support through either feedback, good modeling or decoding strategies. So, there is a need to use different approaches and strategies to develop it such as decoding strategies. 
Decoding Strategies are divided into three levels. The first level of decoding strategies is applied to nonreaders or who read so poorly, that they don't understand what they read. The first level of Decoding Strategies addresses letter and word discrimination ,sound and letter combinations, word ending, story reading and literal and inferential comprehension. At the completation of that level, students should be able to read 60 words per minute(Edmondson,2004).

The Decoding Strategies are designed to change the behavior of poor decoders. These strategies are practiced for those students who: make frequent word-identification errors, make word omissions, additions, or confuse high-frequency words (e.g., what/that, of/for), have inadequate reading rates, making it difficult for them to remember the various details of the passage, even if they were decoded accurately, don't read a passage with the degree of accuracy needed to understand what the passage actually says. Moreover, Decoding Strategies focus on word attack skills and include isolated sound/word practice, group reading activities to develop accuracy and oral reading fluency. (Armbruster et al., 2001).

In decoding strategies level $\mathrm{A}$, students are taught through sentence-reading activities to retain how to read words in sentences. The sentences that are used should be designed perfectly, so that there is low probability of guessing a word correctly. If student guess the next word in a sentence on the basis of preceding words ,they most likely will be wrong. The low probability feature provides students with consistence evidence that guessing is not effective. A guess equals a mistake ;therefore students quickly abandon the guessing approach and use the 
decoding skills being taught .The story-reading exercises should be given in this level through which students practice in decoding material similar to what they will encounter in the second level of decoding strategies(Engelmann,1999\&Lingo,2003).

Decoding strategies level "B" are appropriate for students who add or omit words through reading materials. They often read synonyms for printed words and are generally inconsistent in their reading behavior( reading a word correctly one time and missing it the next time. Students are practicing reading aloud and if they make errors the instructor should present specific comprehension questions for that part. Some of the activities presented are teacher-directed and are very important to the students' skill development, while others are independent. The syntax and structure of the reading materials are designed for the problem decoder and to correct the mistakes the reader typically makes(Engelmann ,1999).

In 2011,Joseph determined the effectiveness of a decoding strategies -Based program level c on English language learners 'oral reading fluency and compared to Houghton Mifflin Reading Program. The sample was 180 students in grades four to six randomly assigned to either Decoding strategies -Based Program or Houghton Mifflin Based Reading Program .All students were measured by the (DIBELS) fluency test, the (STAR) reading test, and the (California) standards test. Students were given the tests according to their grade levels. The results indicated that their reading rate was developed to 140 words per minute and reading comprehension. 
The third level of Decoding Strategies level "C" emphasizes the accurate reading of the reading materials and informational reading comprehension questions. Through this level students are presented to reading texts that give specific factual information on a particular topic even from magazines, newspapers or other resources. There are some activities that students should apply in order to practice reading comprehension skills. Students are required to orally answer questions about the selections that are read. They also write their answers to a variety of comprehension items, including both literal and inferential items that require recall of story events, sequencing and characters. Finally, they become fluent decoders who make only occasional decoding errors when they read materials that contain a fairly broad vocabulary and a variety of sentence form. They became able to read better a minimum rate of about 150 words per minute ,that is sufficient to facilitate comprehension of what theyread.(Lingo,2003\&Wirner,2008)

Drake ford (2002) implemented the Corrective Reading program with six incarcerated African-American students. Students were separated into two groups of three students each, based on the results from the Corrective Reading placement test. This study investigate whether an intensive reading program could positively affect reading fluency rate, reading placement level, and attitude toward reading.. Results showed that the reading fluency of all participants improved following the implementation of the Corrective Reading program.Teachers also noted improvements in the students' attitude toward reading. 
In order to use the Decoding Strategies intervention it is very important to follow through specific steps. Beginning with phonemic awareness that is taught directly in the early levels of the intervention such as phoneme segmentation, blending ,andmanipulating. Then, phonics instruction where decodable texts are provided for practice the emphasis of reading multisyllabic words. Fluency is addressed in the group reading and reading checkout parts of each session. Vocabulary instruction directly teaches important, difficult, and useful words .Students work with new words in reading sentences, paragraphs and longer text. Finally, comprehension is taught using questioning, which are provided at the beginning so that students may anticipate text content and activate prior knowledge. (lavation,2010)

In the same vein, Guinn(2009) asserted that using Decoding strategies is a comprehensive intervention. There are three essential goals of this intervention :(a)increasing reading accuracy,(b)developing reading fluency and rate, and(c)building reading comprehension. $\mathrm{He}$ added that in order for that comprehensive intervention to be fully aligned with Scientifically Based Reading Research(SBRR),its instructional content must include all five components of reading: phonemic awareness, phonics, fluency, vocabulary , and comprehension. In addition,its instructional strategies coordinated instructional sequences, sample practice opportunities, and aligned student materials.

Tam, Heward, and Heng (2006) conducted a study to evaluate the effects of an intervention program consisting of vocabulary instruction, error correction, and fluency building on oral reading rate and comprehension of five ELL students who were struggling readers in a 
primary school. A multiple baseline across students design was used to evaluate the effectiveness of the intervention. The results of this study revealed that all five students demonstrated improvements in oral reading rates during the intervention conditions

Thus, the qualitative and quantitative findings regarding the use of Decoding Strategies with reading fluency have shown that this intervention has a positive impact on students 'reading fluency skills (Deboer 2008; Gregory,Weber and Stooky 2005;Harris,Marchand,and Martella,2000; Steventon and Fredrick 2003)

\section{Background of the problem.}

In spite of the importance of the EFL reading automaticity, there is a lack in the EFL reading automaticity skills among second year students enrolled in the English section in Benha faculty of Education. According to the reading course specifications of second year students enrolled in English section at Benha Faculty of Education (2010), "students should be prepared to read in natural way and demonstrate activities that require advanced reading skills, such as brainstorming, thinking aloud, and storytelling".

The Egyptian National Authority to ensure the quality of education and accreditation, (2010) stated that, according to the standers of Prep and Secondary English Language Teacher preparation Program, the student teacher should:

- Recognize word stress and intonation and how they change the meaning and affect discourse.

- use various language patterns, utterances and structures easily, smoothly and correctly. 
- read comprehensibly without oral reading problems.

- Read at an appropriate rate sufficient to the understanding of any reading material.

The current Egyptian English language programs do not provide students with opportunities to practice oral reading automaticity in the communicative context. The non-fluent reader often lacks a desire to read orally, reads slowly, engages in word by word reading, lacks appropriate phrasing and expression, doesn't observe punctuation cues and fails to read with proper expression. Moreover, the non fluent reader includes pausing at in appropriate spots, excessive use of "sound in out words, multiple attempts at pronouncing patterns of stress and intonation not consistent with text.(Seifeddin,1991; El -matarawy, 1998; ElGarawany, 2010)

To document the problem of the study, a pilot study was conducted to find out the lack of EFL reading automaticity skills among second year students enrolled in the English section. The participants were 30 students of the second year enrolled in the English Section, Faculty of Education, Benha University during the 2013-2014 academic year. To conduct the pilot study,EFL reading automaticity test was used to assess the 30 students' EFL oral reading automaticity skills.

The test consisted of a reading passage that was appropriate to their reading level. Students are asked to read orally from the beginning of the text for one minute then stop reading.The comprehension part of the test was assessed through some reading comprehension questions followed the text of literal and inferential level. There were two versions of the test :the numbered version for the researcher and the unnumbered 
version for the students. The researcher listened to their readings that were recorded on an audiotape and counted the total words read and errors then the words read correctly per minute(WCPM) that represented their rate.

The results of the pilot study revealed that most of the students were not fluent when they read aloud .Their reading was filled with hesitation, repetitions and pronunciation mistakes .About $75 \%$ of students were not able to move fast through the text .To sum up, second year students enrolled in English section faculty of Education ,Benha University lack EFL reading automaticity skills, so the researcher proposes the suggested program based on Decoding Strategies for developing their EFL reading automaticity skills .

\section{Statement of the problem:}

In spite of the importance of EFL reading automaticity skills, second year students enrolled in the English section in Benha Faculty of Education lack theses skills. Thus, there is a need for an effective program for developing some EFL reading automaticity skills among second year students at the faculty of Education.So, the following study aimed at examining the effectiveness of using Decoding Strategies in developing some EFL reading automaticity skills.

\section{Questions Of The Study:}

To face this problem, the present study attempted to answer the following questions:

1- What are the reading automaticity skills required for EFL second year students at Benha Faculty of Education? 
2- What is the current level of EFL second year students in reading automaticity skills at Benha Faculty of Education?

3- What are the features of the suggested program based on Decoding Strategies?

4- What is the effectiveness of using the Decoding Strategies in developing reading automaticity skills among EFL second year students in The Faculty of Education at Benha University?

\section{Scope of the Study:}

This study is limited to the following:

- A sample of second year students enrolled in English Section at the Faculty of Education, Benha University.

- Some EFL reading automaticity skills required for second year students enrolled in the English section Faculty of Education at Benha University.

\section{Procedures of the study:}

The researcher followed the following procedures to carry out the study as follows:

\section{1- Identifying the EFLReading automaticity skills required for} second year English Section Students through:

- Reviewing the literature and the previous studies related to the EFL oral reading automaticity skills and preparing a list of EFL reading automaticity skills requird for second year students enrolled in the English Section at Benha university Faculty of Education.Then,submitting the list to a jury of verify its 
validity.Finally,modifying the list according to the jury 'spoint of views.

2- Identifying the current level of of EFL reading automaticity skills of second year students enrolled in the English Section at Benha University faculty of Education through:

- Designing an EFL reading automaticity test to assess the students' EFL oral reading fluency skills and submitting the test to a jury to modify it .Then, modifying the test according to the jury 's suggestions.Selecting the study sample of second year English section faculty of Education at Benha University.and finally, applying the test to the study sample before the implementation of the suggested program to measure their level in EFL reading automaticity skills .

\section{3- Designing the Decoding strategies-Based Program through :}

- Reviewing the literature and the previous studies related to the Decoding strategies and reading automaticity skills and identifying the objectives, strategies and the content of the program.Then,identifying the procedures and the evaluation techniques followed during the implementing the program.

4- Identifying the effectiveness of the Decoding strategies -Based program in developing the EFL reading automaticity skills :

- Teaching to the study sample using the Decoding Strategies Based Program and applying the EFL reading automaticity test to the study sample after the implementation of the program .Then, collecting and tabulating the statistical analysis of the data and 
interpreting findings of the study .Finally suggest the recommendations of the study.

\section{Participants of the study:}

The participants were thirty students enrolled in second year English section at Benha Faculty of Education at the first semester of 2014-2015 academic year. They were chosen for the following reasons:

1- They are supposed to be Prospective teachers of EFL; consequently, they have to master this important component of the reading process-reading fluency- they are going to teach so as to be the source of constant exposure of good oral reading modeling to their students.

2- It is at this stage that they need to be prepared very well to be qualified to the next stage (third year) of practicing teaching in the preparatory stage in which oral reading has an important role in the English curriculum.

\section{Instruments of the study:}

The present study made use of the following instruments to fulfill its purpose:

- An EFL pre-post Reading Automaticity Test and a rubric to correct it prepared by the researcher .

\section{Validity of EFL Reading automaticity Test: $\square$}

In order to validate the EFL reading automaticity test, it was submitted to some of the jury members in curricula and methods of Teaching English .They were asked to indicate the suitability of the test content for the academic level of the study sample ( Second Year English Language Department Students at Benha Faculty of Education 
and the clarity of the instructions for each part of the test .They indicated the suitability of the test and how far each question of the test assesses the skills intended to measure comprehension .Most of the jury members also indicated the suitability of the test to its main objectives and the consistency of questions to the test 's objectives.

According to the jury's' opinions and suggestions ,the modifications would be performed to the test 's content to get its final form.

\section{The Reliability of The EFL Reading automaticity Test: $\square$}

For estimating the reliability of The EFL Reading automaticity Test ,the following two methods were used:

\section{1- Test - Retest Method: $\square$}

The EFL Reading automaticity test was applied at the beginning of the second semester of the academic year 2013-2014 to a sample of Second Year English Language Department Students at Benha Faculty of Education $(n=30)$.Then, the test was re-applied to the same sample after an interval of time about two weeks . The correlation coefficient (r) between the results of the first and second application of the test is measured using Pearson formula .The reliability Coefficient was $(0,78)$ which is significant at the 0,01 level . This means that the EFL oral reading automaticity test was reliable .

\section{2- The Inter -rater reliability method:}

The test was corrected by two raters : The first was the researcher and the second was a lecturer at Department of curricula and teaching methods ${ }^{1}$.Then ,the correlation coefficient between the scores of the first and the second rater was measured using the Pearson formula .The 
reliability coefficient was $0,758^{* *}$ for oral reading rate and 0,869 for reading comprehension which was statistically significant at $(0,01)$ level Hence, it can be said that the test was reliable.

\section{Aims of the Study: (')}

The study aimed at developing some of the EFL Reading automaticity skills for second year students, enrolled in English section at Benha Faculty of Education .The researcher uses variety of decoding strategies to accomplish the study aims, so by the end of the program students will be able to :

1- Identify the importance of EFL Oral reading automaticity skills to them as English language learners and read the isolated words correctly without errors .

2- Read connected sentences perfectly in various reading passages .If students practice reading only narrative passages, they will not automatically transfer the reading skills to text books, articles or other

3- Read different reading passages quickly enough to comprehend what they read with average rate 150 words per minute sufficient at comprehending the reading material.

\section{The Experimental Treatment:}

After the participants in the study has been selected ,the researcher begins to apply the Decoding Strategies- Based Program in the Instructional Aids Laboratory at Benha University Faculty of Education .All sessions have been videotaped. The researcher videotaped the

(') Hasnaa Sabry Abdel-Hamid Ahmed Helwa - A lecturer at the department of curricula and Instruction at Benha University Faculty of Education 
sessions to be easy analyzed and interpreted so that ,she could easily analyze and interpret the participants' performance .To sum up, at the beginning of each session ,the instructor informed the study sample about their roles and the instructional aides that would be used through the sessions. Moreover, by the end of each session the researcher gave the study sample some activities to make sure that the sample of the study had mastered the intended skill .By the end of the sessions ,the instructor applied the EFL reading automaticity test to determine the effectiveness of the suggested program .The study sample reading rate wasn't developed sufficiently, but their reading comprehension skills were developed, all in all their reading automaticity skills were developed as a result of using the suggested program that based on Decoding strategies.

\section{Intervention Methods of the Study:}

1- Direct Instruction .

2- Teacher modeling

3- Guided, independent practice and application with corrective feedback.

4- Frequent interactions between researcher and students.

5- Appropriate pacing of sessions.

6- Adequate practice and review.

\section{The Evaluation Techniques of the Program:}

The Evaluation techniques used in the program consisted of two types: formative and summative.

The formative evaluation was conducted by the researcher during the program's sessions, as by the end of each session ,the researcher 
asked the students to look at their worksheets of the session and answer the tasks that followed the skill being emphasized to make sure that they acquire it. The second type of evaluation was summative one The researcher used this type after the administration of the program to identify to what extent the program objectives have been achieved and investigating the effectiveness of the decoding strategies in developing the study sample EFL reading automaticity skills (rate\& comprehension) through the administration of the EFL reading automaticity test.

\section{Findings and Discussion of the Study:}

The overall aim of using Decoding strategies was to develop second year students' enrolled in the English Section at Benha university Faculty of Education EFL reading automaticity skills .

To measure the effectiveness of the program ,the study sample was pretested on the EFL reading automaticity pre-test and post -tested using the EFL oral reading automaticity test .For comparing the initial and the final mean scores of the study sample in the overall EFL reading automaticity skills and to find whether there were significant difference between them in the pre-post assessment of the test ,the researcher used the one sample T-Test

\section{Pre-and Post-Test :}

The one sample $\mathrm{t}$-Test is used to compare the mean scores of the study sample in oral reading rate on the pre-post administration of EFL oral reading automaticity test .Table(1) presents the students' mean scores, standard deviation-value and the level of the significance of the study sample in the pre-post assessment of the EFL oral reading rate. 
Table(1) : $t$ " test between the mean scores of the study sample in the pre-post assessment of EFL oral reading rate .

\begin{tabular}{|c|c|c|c|c|c|c|c|}
\hline Skill & Measurement & N. & Means & S.D. & T-Value & D.F & Sig. \\
\hline $\begin{array}{c}\text { EFL oral } \\
\text { reading rate }\end{array}$ & Pre & 30 & $\mathbf{1 2 0 . 6 6 7}$ & $\mathbf{2 4 . 3 9 2}$ & \multirow{2}{*}{1.386} & \multirow{2}{*}{29} & $\begin{array}{c}\text { Not } \\
\text { significant }\end{array}$ \\
\cline { 2 - 5 } & Post & 30 & $\mathbf{1 2 7 . 1 3 3}$ & $\mathbf{2 4 . 5 6 8}$ & & \multicolumn{2}{|c|}{} \\
\hline
\end{tabular}

Table (1) shows that the mean scores is (120.667) for the pre assessment and (127.133)for the post assessment and the standard deviation is (24.392)for the pre-assessment and (24.568)for the post assessment, where the t-value is (1.386),p.>0.05.Therefore ,there is no statistically difference between the mean scores of the study sample pre and post assessment in oral reading rate in the administration of EFL oral reading automaticity test .Thus ,the study sample didn't develop their oral reading rate.

The $\mathrm{t}$-Test is used to compare the mean scores of the study sample in EFL reading comprehension on the pre-post administration of EFL oral reading automaticity test as shown in table 2

Table (2) :" $t$ " test value between the mean scores of the study sample in the pre-post assessment of EFL reading comprehension .

\begin{tabular}{||c|c|c|c|c|c|c|c||}
\hline Skill & Measurement & N. & Mean & S.D. & T-Value & D.F & Sig. \\
\hline \multirow{2}{*}{$\begin{array}{c}\text { EFL reading } \\
\text { comprehension }\end{array}$} & Pre & 30 & 6.227 & 1.701 & & & \\
\cline { 2 - 5 } & Post & 30 & 11.033 & 1.402 & 15.782 & 29 & 0.01 \\
\hline
\end{tabular}

Table (2) shows that the mean scores is (6.227) for the pre assessment and (11.033)for the post assessment and the standard deviation is (1.701)for the pre-assessment and (1.402)for the post assessment. As shown in the table (7)"there is a statistically significant 
difference between the mean scores in the study sample in the pre-post assessment of EFL oral reading comprehension in favor of the post assessment ", where the $(\mathrm{t}=15.782, \mathrm{p}<0.01)$ which is significant at the (0.01)level of significance

The $\mathrm{t}$-Test is used to compare the mean scores of the study sample in EFL reading automaticity as whole on the pre-post administration of EFL oral reading automaticity test .Table(3) presents the students' mean scores, standard deviation-value and the level of the significance of the study sample in the pre-post assessment of the EFL reading automaticity.

Table(3) :" $t$ " test value between the mean scores of the study sample in the pre-post assessment of EFL reading automaticity .

\begin{tabular}{|c|c|c|c|c|c|c|c||}
\hline Skill & Measurement & N. & Mean & S.D. & T-Value & D.F & Sig. \\
\hline \multirow{2}{*}{$\begin{array}{l}\text { EFL reading } \\
\text { automaticity }\end{array}$} & Pre & 30 & $\mathbf{1 2 6 . 9 3 3}$ & $\mathbf{2 4 . 9 8 0}$ & \multirow{2}{*}{2.389} & & \\
\cline { 2 - 7 } & Post & 30 & 138.167 & 24.757 & & 29 & 0.05 \\
\hline
\end{tabular}

Table (3) shows that the mean scores is (126.933) for the pre assessment and (138.167)for the post assessment and the standard deviation is (24.980)for the pre-assessment and (24.757)for the post assessment. As shown in the table (8)"there is a statistically significant difference between the mean scores in the study sample in the pre-post assessment of EFL reading automaticity in favor of the post assessment ", where the $(\mathrm{t}=2.389, \mathrm{p}<0.05)$ which is significant at the (0.05)level of significance . 


\section{Discussion}

The results of the present study revealed that there was not a statistically significant difference between the mean scores of the study sample in the EFL reading rate in the pre-post assessment .Although he mean scores for the pre-assessment was (120.667) and the post was (127.133),the t-value was (1.386)which was not significan

This result might be attributed to different reasons. Some of the participants might still have some poor reading habits such as the subvocalization habit .This bad habit of reading may hinder the students ' ability to develop the reading speed or rate .They might sub-vocalize words during reading or took much more time than necessary, so they needed to practice more on reading rate until this bad habit disappeared.Another reason may be the word-by-word reading of some of the participants-as they concentrated on pronouncing the separate words ,by doing so ,they might miss the overall concept of what was read .Reading chunking words together would be a suitable solution to overcome this problem. The researcher should practice them on expanding the number of words that they read at a time .(one minute).

To sum up ,there were some reasons that might hinder their ability to read at the independent reading rate such as ,using the authentic materials might be more challenging for their speed or rate and the insufficient time to use a certain benchmark for their current reading speed .Using benchmark might help them in developing their reading speed when being informed of their reading performance each time they read. 
Results of the present study confirmed that "there was a statistically significant difference between the mean scores of the study sample in the EFL reading comprehension in the pre-post assessment in favor of the post assessment .Thus, the participants showed more improvements in their EFL reading comprehension. This is due to the use of the Decoding Strategies -Based Program, where the " $t$ " value was significant at the level of $(0.01)$

This result might be attributed to the study sample 's practice on reading comprehension skills such as identifying the main idea and skimming ,scanning ,identifying cause and effect relationship, expressing his ther point of view concerning reading text, and detecting the author's point of view.

The materials that were used throughout the sessions might be one of the main reasons for developing the study sample's reading comprehension skills as she used various reading texts with more enjoyable topics that might motivate them. Moreover ,throughout the sessions of the program ,the researcher provided the study sample with the basic instructions to comprehend the reading passage ,such as: skimming the reading passage to determine its main idea and the overall organization of the ideas and looking ahead at the questions to determine how to answer them as each one has a specific way of answering, such as looking at the first line of each paragraph.

To summarize, the researcher practiced students on how to have a quick glance at the key parts of the text to get an overview on how the material was organized and developed. This strategy helped them to get the main idea of the text before the initiation of its actual reading and the mastery of the text . 


\section{References}

Armbruster, B. B., Lehr, F., \& Osborn, J. (2001). Put reading first: The research building blocks for teaching children to read, kindergarten through grade 3. Jessup, MD: National Institute for Literacy.

Chang,A.C.(2012). Improving reading rate activities for EFL students: Timed reading and repeated oral reading. Journal of Reading In A foreign Language.24(1),56-83.

Clauda,S.L.(2007).Relationships of three components of reading fluency on reading comprehension ,Unpublished master thesis, University of Maryland.

Deboer, R.A.A (2008). Improving the reading fluency of elementary Latino English language learners. Unpublished doctoral dissertation, university of Wisconsin, Madison.

Drakeford, W. (2002). The impact of an intensive program to increase the literacy skills of youth confined to juvenile corrections. Journal of Correctional Education, 53(4), 139-144.

Edmondson, C. A. (2004). Effects of instruction in the Corrective Reading and Voyager Reading programs on the reading skills of students enrolled in a university program .Unpublished Doctoral dissertation, Utah State University.

El-Garawany, M.S.(2010).The effects of repeated reading strategies on developing oral reading fluency and reading comprehension among EFL prospective teachers. Unpublished master thesis, Minufiya University.

EL-Matarawy, A. (1999).Using Cooperative Learning Techniques to Develop English Oral Language Fluency of Adult Learners. Unpublished M.A Study . Faculty of Education. Amman University. Amman, Jordan.

Engelmann,S.; Hanner, S.\& Johnson, G.(1999).Corrective Reading Series Guide. SRA/McGraw-Hill. U.S.A. 
Gregory, A.; Weber, K.P; and Stookey, S.(2005) .The Effects Of Using Direct Instruction and A re-reading contingency with A high school student . International Journal of special Education ;20(1),50-54.

Guinn,T.R.(2009). The Effectiveness of SRA Corrective Reading and SRA Connecting Math Programs As Reading and Math Intervention Programs for Students with Disabilities. Unpublished doctoral dissertation, Tennessee State University.

Hacker,J.A.(2008).Increasing oral reading fluency with elementary English Language learners. Unpublished Master Thesis, Hamline University.

Harris,E.(2010).Evaluating The Efficacy of Reading Fluency Instruction.

Unpublished doctoral dissertation, University of Southern Maine.

Harris, R.E; Martella, N. M.; Martella, R.C.(2000). Effects Of PeerDelivered Corrective Reading Program. .Journal of Behavioral Education ,10(1),21-36

Hudson, R. F.; Lane, H.B. \& Pullen, P.C.(2005).Reading Fluency assessment and instruction: What, Why, and How? The Reading Teacher,58(8),702-714.

Joseph, K. C. (2011). Comparison OF Haughton Mifflin Core Reading Program and Corrective Reading Program Effects On English Language Learners Reading Fluency and Comprehension in Grades 4-6. Unpublished doctoral dissertation ,Claremont University ,California.

Lingo, A.S.(2003) . Effects OF Corrective Reading On Reading Abilities and Classroom Behaviors Of Middle School Students With Reading Deficits and Challenging Behavior. Unpublished doctoral dissertation, Kentucky University .

Luchner, J.;\& Urbach, J.(2011).Reading Fluency and students who are Deaf or Hard of Hearing: Synthesis of the Research. Hummill Institute onDisabilities, 33(4),230-241. 
Mazur,C.(2005).The effect of a reading program with focused fluency instruction on reading comprehension and fluency of adult ESL learners .Unpublished Master thesis, Hamline University.

National Reading Panel. (2000). Report of the National Reading Panel:

Teaching children to read. Report of the subgroups.

Washington, DC: U.S. Department of Health and Human

Services, National Institutes of Health.

Rasiniski,T.V.(2004).Assessing reading fluency. Honolulu: Pacific

Resources for Education and Learning.

Rasiniski, T. V.(2012).Why reading fluency should be hot. The Reading Teacher,65(8),518-522.

Samuels, S. J. (2006). Reading fluency: Its past, present, and future. In T. V. Rasinski, CBlachowicz, \& K. Lems (Eds.), Fluency instruction: Research-based best practices (pp. 7-20). New York, NY: The Guilford Press.

Sargent ,S.E.(2002) . Oral Reading Fluency: A predictor Of Reading Proficiency In Fifth Grade Students?. Unpublished doctoral dissertation, Oklahoma State University.

Seifeddin, A.H.(1999).Effects of some teaching activities and techniques on improving oral reading of junior learners. Jouranal of Educational and Psychological Sciences, Faculty of Education, Minufiya University,6(2),1-28.

Steventon, c.\& Fredrick, L.D. (2003) .The Effects Of Repeated Readings

On Student Performance In The Corrective Reading Program. Journal Of Direct Instruction .3(1),17-27 .

Tam, K.Y., Heward, W., \& Heng, M. (2006). A reading instruction intervention program for English-language learners who are struggling readers. The Journal of Special Education, 40, 79-93.

Zukowshi, S. B.(2009). Second Grade Reading Fluency: Examining The Effects Of an -Intervention Program On Oral Reading Fluency Progress. Unpublished doctoral dissertation, Robert Morris University. 